\title{
Growth and study of mixed crystals of Ca-Cd iodate
}

\author{
S L GARUD* and K B SARAF \\ P.G. Department of Physics, Pratap College, Amalner 425 401, India
}

MS received 10 October 2007; revised 30 June 2008

\begin{abstract}
Mixed crystals of calcium-cadmium iodate were grown by a simple gel technique using diffusion method. The optimum conditions were established by varying various parameters such as $\mathrm{pH}$ of gel solution, gel concentration, gel setting time, concentration of reactants etc. Crystals having different morphologies and habits were obtained. Prismatic, dendritic crystals of calcium-cadmium iodate and prismatic needle shaped, hopper crystals of mixed iodate were obtained. Some of them were transparent, some transluscent and a few others were opaque. The crystals were characterized using FT-IR, EDAX, XRD, TGA and DTA.
\end{abstract}

Keywords. Gel technique; mixed iodate crystals; FT-IR; EDAX; XRD; TGA; DTA.

\section{Introduction}

A variety of crystals required for the purpose of research and application can be grown in silica gels. The gel medium prevents turbulence and being chemically inert, it provides a three-dimensional crucible which permits the reagents to diffuse at a desirable controlled rate. Its softness and uniform nature of constraining forces that it exerts upon the growing crystals encourages orderly growth (Patel and Venkateswara Rao 1978; Shitole and Saraf 2001).

The growth of single crystals in gel at ambient temperature, which are sparingly soluble in water, is a fascinating alternative to the techniques involving high temperature and expensive equipments (Sangwal and Patel 1974). During the last few years, successful application of gel growth technique has been demonstrated by the preparation of single crystals of alkaline earth metal iodate (Joshi and Trivedi 1983). The gel growth technique appeared quite attractive for growing crystals of such compounds on account of its unique advantages in terms of crystals produced and the simplicity of the process (Armington and O'Connar 1968; Blank and Brenner 1969; Blank et al 1969; Ranadive et al 1969; Blank 1973). Crystals of iodate exhibit nonlinear optical properties (Kurtz and Perry 1968; Morosin et al 1973) and piezoelectric properties (Bach and Kuppers 1978). Nonlinear optical phenomena have found a wide variety of applications in many areas of modern science, technology and engineering. The nonlinear devices find large applications in optical communication, image processing and wave-guide coupling. Mixed iodate crystals of calcium cadmium iodate are used in medicine and deodorant.

In the present work, mixed iodate crystals of calcium cadmium iodate were grown by gel technique using di-

*Author for correspondence (sl.garud@rediffmail.com) ffusion method. Optimum growth conditions for crystals were determined. Optimum conditions were established by varying various parameters such as $\mathrm{pH}$ of gel, gel reactants, concentration programming, effect of neutral gel etc.

\section{Experimental}

Test tubes were used as crystallizing vessels. The silica gel was used as a growth media. Gel was prepared by using glacial acetic acid and sodium meta silicate having different $\mathrm{pH}$ values. The chemicals used for growth of mixed iodate crystals were $\mathrm{CH}_{3} \mathrm{COOH}, \mathrm{Na}_{2} \mathrm{SiO}_{3} \cdot 9 \mathrm{H}_{2} \mathrm{O}, \mathrm{KIO}_{3}$, $\mathrm{NaIO}_{3}$. All chemicals were of AR grade.

Different molar masses were tried to determine the optimum growth conditions. One of the reactants having different concentrations was incorporated into the gel. This solution was then transferred to borosil glass tube of diameter, $2.5 \mathrm{~cm}$ and $25 \mathrm{~cm}$ in height. The mouth of the tube was covered by cotton plug. After setting of the gel, it was left for aging for different periods of time. Another reactant having different concentrations was then added as supernatant over the set gel. Experiments were carried out by changing different concentrations of the reactants.

The chemical reaction inside the gel can be expressed as

$$
\begin{gathered}
x \mathrm{CdCl}_{2}+(1-x) \mathrm{CaCl}_{2}+4 \mathrm{YIO}_{3}= \\
\mathrm{Cd}_{x} \mathrm{Ca}_{(1-x)}\left(\mathrm{IO}_{3}\right)_{4}+4 \mathrm{YCl},
\end{gathered}
$$

where $\mathrm{Y}=\mathrm{K}$ or $\mathrm{Na}$.

\section{Results and discussion}

The various optimum conditions for growing crystals were found and are given in table 1. 
Different parameters such as concentration of reactants, $\mathrm{pH}$ of gel, impurities in the solvent, gel setting time, gel aging time, etc have considerable effect on growth rate. In the steady state of concentration gradient, growth rate also becomes steady which favours growth of welldeveloped crystals. However, very slow rate of growth along one direction results in the platy crystals. Fast growth rate in one particular direction leads to the formation of elongated crystals like dendrites or hopper crystals.

\section{Observations}

Various concentrations of reactants have various effects on the quality of crystals. Table 2 summarizes the effects on the habits of single crystals.

Figure 1 shows dendritic growth of calcium cadmium iodate crystals inside the test tube for high concentration of reactants. Figure 2(a) shows prismatic transparent crystals of calcium cadmium iodate inside the test tube. Figure 2(b) shows a few prismatic transparent crystals of calcium cadmium iodate. At one end, crystals are transluscent which is due to the inclusion of silica gel.

\section{Characterization}

Mixed iodate crystals grown were characterized by FTIR, EDAX, XRD, TGA and DTA.

\subsection{Fourier transform infrared (FT-IR) spectral analysis}

FT-IR is used for structural analysis. In the present study, IR spectrum of calcium cadmium iodate sample was recorded using SHIMADZU spectrophotometer at the Department of Chemistry, University of Pune. Figure 3 shows FT-IR spectrum of calcium cadmium iodate. The IR spectrum was recorded in the wave number range $400-4000 \mathrm{~cm}^{-1}$ for $\mathrm{KBr}$ line.

The bands at $3437 \mathrm{~cm}^{-1}$ are due to $\mathrm{O}-\mathrm{H}$ stretching and at $1678 \mathrm{~cm}^{-1}$ are due to $\mathrm{H}-\mathrm{O}-\mathrm{H}$ bending. Bands due to

Table 1. Optimum conditions for growth of calcium cadmium iodate crystals.

\begin{tabular}{ll}
\hline Conditions & $\begin{array}{c}\text { Calcium cadmium } \\
\text { iodate }\end{array}$ \\
\hline $\begin{array}{l}\text { Density of sodium meta silicate solution } \\
\text { Amount of } 2 \mathrm{~N} \text { acetic acid }\end{array}$ & $1 \cdot 04 \mathrm{~g} / \mathrm{cm}^{3}$ \\
pH of mixer & $5 \mathrm{ml}$ \\
Temperature & $4 \cdot 2$ \\
Concentration of $\mathrm{NaIO}_{3}$ or $\mathrm{KIO}_{3}$ & Room temperature \\
Concentration of $\mathrm{CaCl}_{2}$ or $\mathrm{Ca}\left(\mathrm{NO}_{3}\right)_{2}$ & $0 \cdot 5 \mathrm{M}$ \\
Concentration of $\mathrm{CdCl}_{2}$ or $\mathrm{Cd}\left(\mathrm{NO}_{3}\right)_{2}$ & $0 \cdot 5 \mathrm{M}$ \\
Gel setting time & $0 \cdot 5 \mathrm{M}$ \\
Gel aging time & 12 days \\
Period of growth & $120 \mathrm{~h}$ \\
\hline
\end{tabular}

vibration involving metal, iodine and oxygen atoms are found predominantly near $748-815 \mathrm{~cm}^{-1}$. Fundamental infrared frequencies, observed in all iodate compounds in general, are also found in the present FT-IR analysis, which confirm the iodate group of grown crystals. The bands at $370 \mathrm{~cm}^{-1}$ are due to the iodate group. Fundamental frequencies that have been observed are $v_{1}$ (symmetric stretching) at $748.5 \mathrm{~cm}^{-1}$ and $v_{3}$ (asymmetric stretching) at $815 \mathrm{~cm}^{-1}$. The dominant absorption bands are found at $700-815 \mathrm{~cm}^{-1}$ in all iodate compounds (Nakamoto 1970) and can be expected to contain $v_{1}, v_{3}$ as well as possible splitting of $v_{3}$. From the spectral analysis, it is clear that in case of calcium cadmium iodate crystals the $\mathrm{O}-\mathrm{H}$ stretch bands in the region $2300-3700 \mathrm{~cm}^{-1}$ are much widened. It is due to inclusion of water molecules.

\section{$5.2 E D A X$}

Elemental analysis was carried out at NCL, Pune. Table 3 shows values of elemental content of the crystal by EDAX and theoretical calculation from molecular formula. From the table it is clear that the values (wt \% and at \%) of $\mathrm{O}$, $\mathrm{Ca}, \mathrm{Cd}$ and I in the grown crystal measured by EDAX are

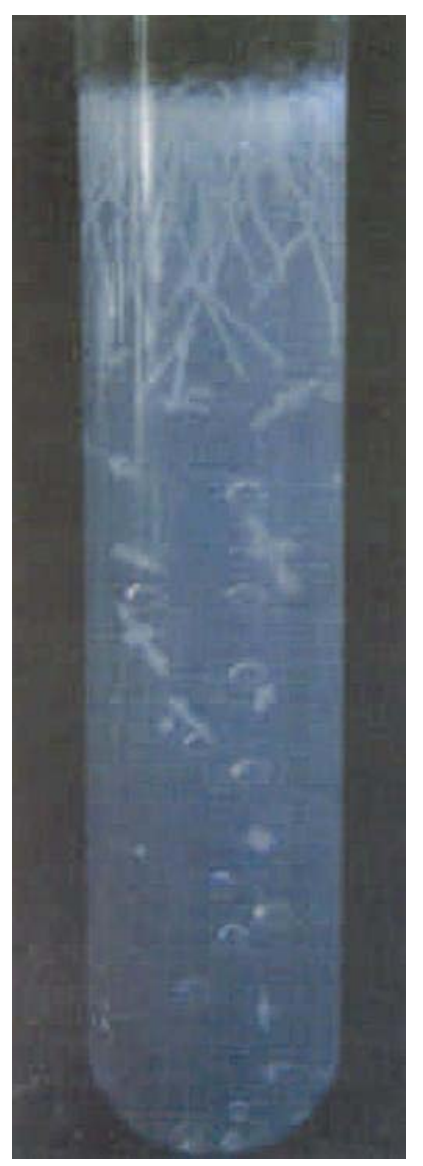

Figure 1. Dendritic growth of calcium cadmium iodate crystals. 
Table 2. Effect of concentration of reactants of habit, quality and size of $\mathrm{Ca}_{1-x} \mathrm{Cd}_{x}\left(\mathrm{IO}_{3}\right)_{4}$.

\begin{tabular}{lllll}
\hline Conc. of reactant in gel & Conc. of reactant above gel & Habit & Quality & Size (mm) \\
\hline $\mathrm{NaIO}_{3}$ or $\mathrm{KIO}_{3}$ & $\mathrm{CaCl}_{2}, \mathrm{CdCl}_{2}$ & Dendritic & Opaque, brittle & $10 \times 20 \times 1$ \\
$0.4 \mathrm{M} 3$ to $5 \mathrm{ml}$ & $0.5 \mathrm{M} 10 \mathrm{ml}$ & & & $8 \times 2 \times 2$ \\
$\mathrm{KIO}_{3} 0.4 \mathrm{M} 8 \mathrm{ml}$ & $\mathrm{CaCl}_{2}, \mathrm{CdCl}_{2} 0.4 \mathrm{M} 6 \mathrm{ml}$ & Prismatic & Good & $8 \times 2 \times$ \\
\hline
\end{tabular}

Table 3. Values of elemental content of the crystal.

\begin{tabular}{|c|c|c|c|c|}
\hline \multirow[b]{2}{*}{ Element } & \multicolumn{2}{|c|}{ Content as measured by EDAX } & \multicolumn{2}{|c|}{$\begin{array}{l}\text { Content as calculated from } \\
\text { molecular formula } \mathrm{Ca}_{0 \cdot 6} \mathrm{Cd}_{0 \cdot 4}\left(\mathrm{IO}_{3}\right)_{4} \cdot 12 \mathrm{H}_{2} \mathrm{O}\end{array}$} \\
\hline & wt $\%$ & at $\%$ & wt \% & at $\%$ \\
\hline $\mathrm{O}$ & 41.63 & 81.77 & 39.95 & 82.75 \\
\hline $\mathrm{Ca}$ & $2 \cdot 12$ & 5.42 & 2.49 & 2.06 \\
\hline $\mathrm{Cd}$ & $6 \cdot 91$ & 0.59 & 4.67 & $1 \cdot 37$ \\
\hline I & $49 \cdot 34$ & $12 \cdot 22$ & $52 \cdot 86$ & $13 \cdot 79$ \\
\hline
\end{tabular}
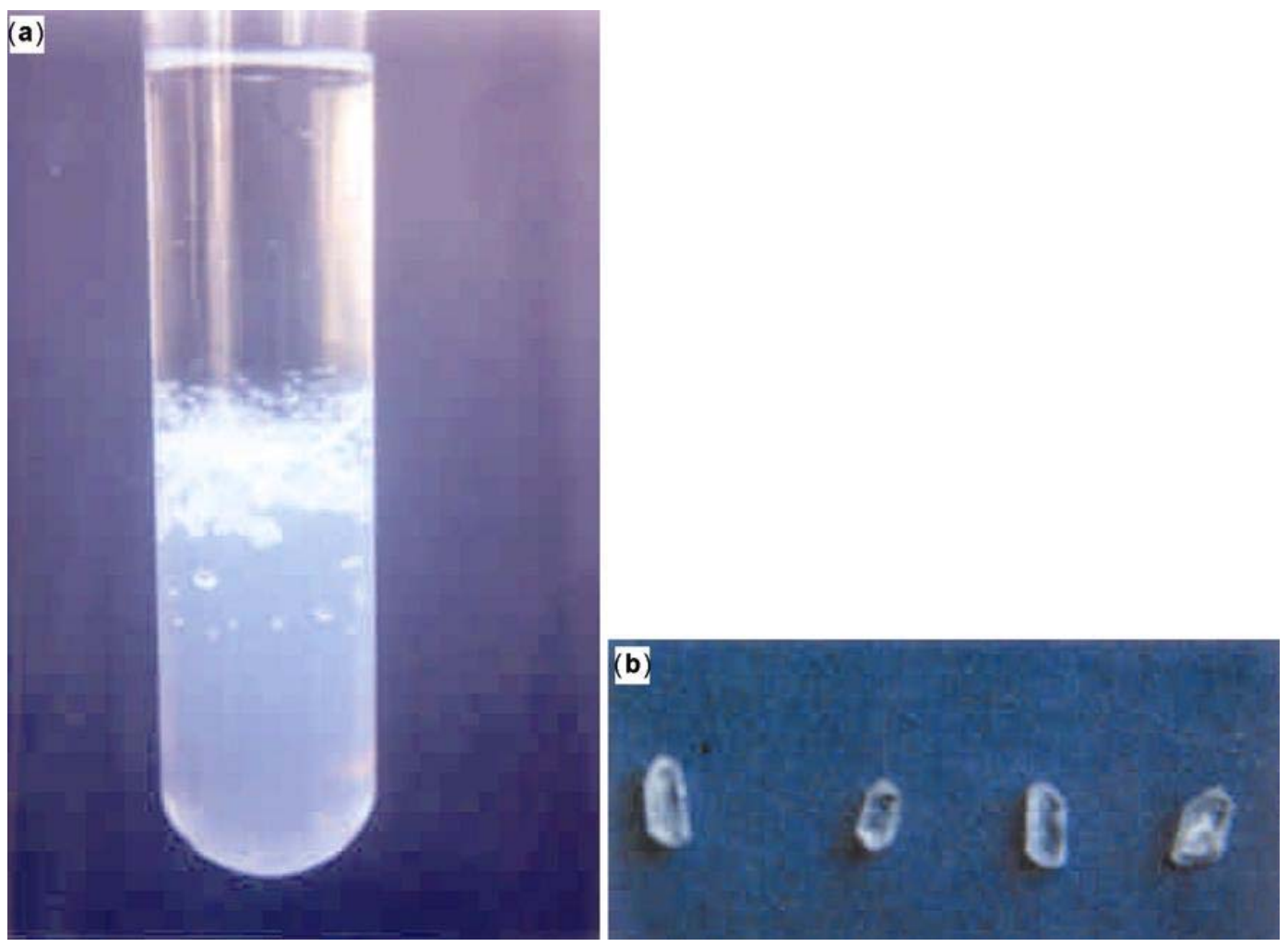

Figure 2. (a) Prismatic transparent crystals of calcium cadmium iodate inside the test tube and (b) few prismatic transparent crystals of calcium cadmium iodate.

very close with the values calculated from the molecular formula.

\subsection{X-ray diffraction}

X-ray diffractogram was recorded using Rigaku, Miniflex, Japan with $\mathrm{CuK} \alpha$ radiation $(1.5418 \AA)$ as shown in figure
4. The observed $d$ values and $h k l$ were computed. The computer program, POWD (an interactive Powder Diffraction Data interpretation and Indexing Program version 2.2) was used to calculate $d$ values. The observed peaks in diffractogram shows that the mixed iodate crystals possess monoclinic structure. Calculated unit cell parameters are given in table 4 . The atomic fraction, $x$, of $\mathrm{Cd}$ replacing $\mathrm{Ca}$ atoms is $0 \cdot 4$, as calculated from the lattice parameters 


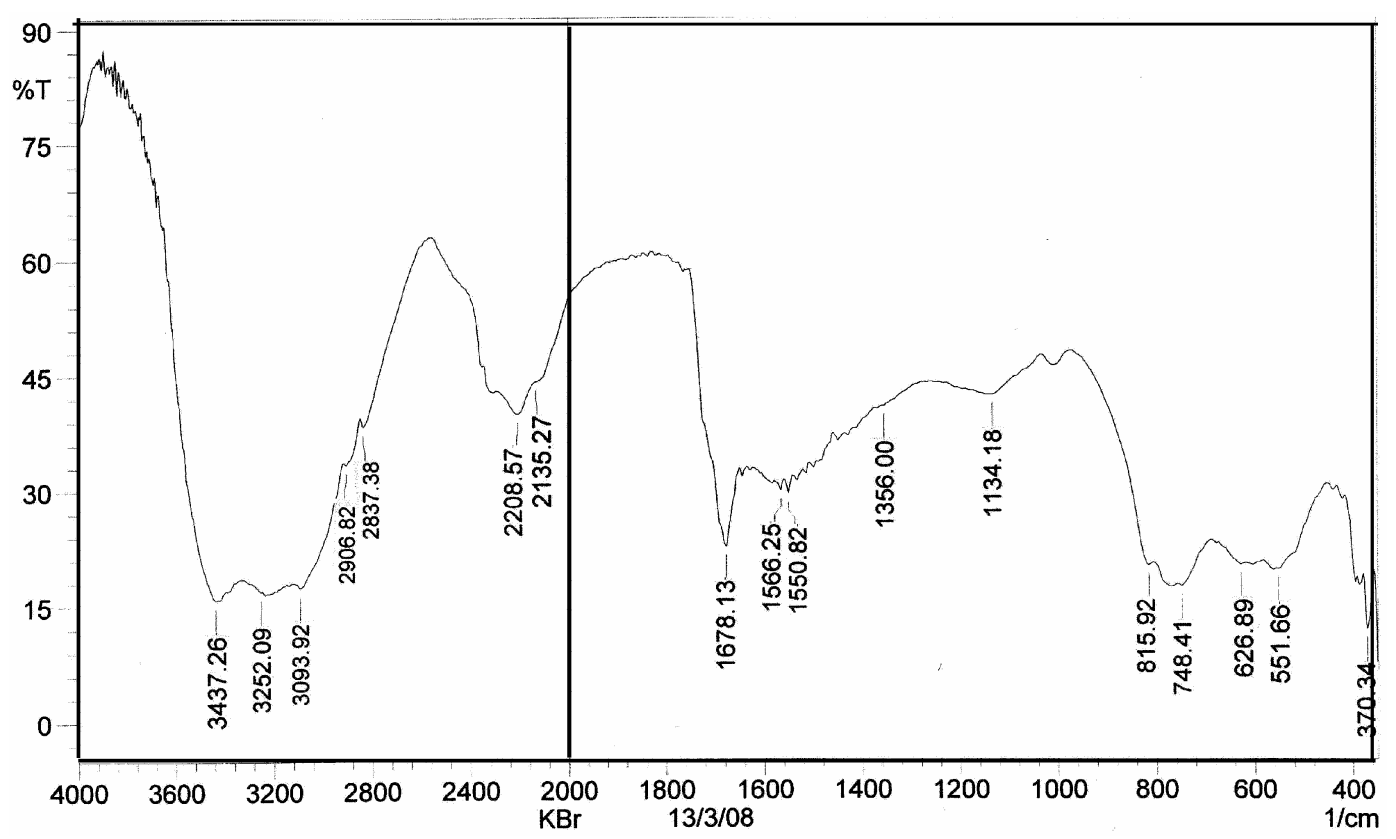

Figure 3. FT-IR spectrum of calcium cadmium iodate.

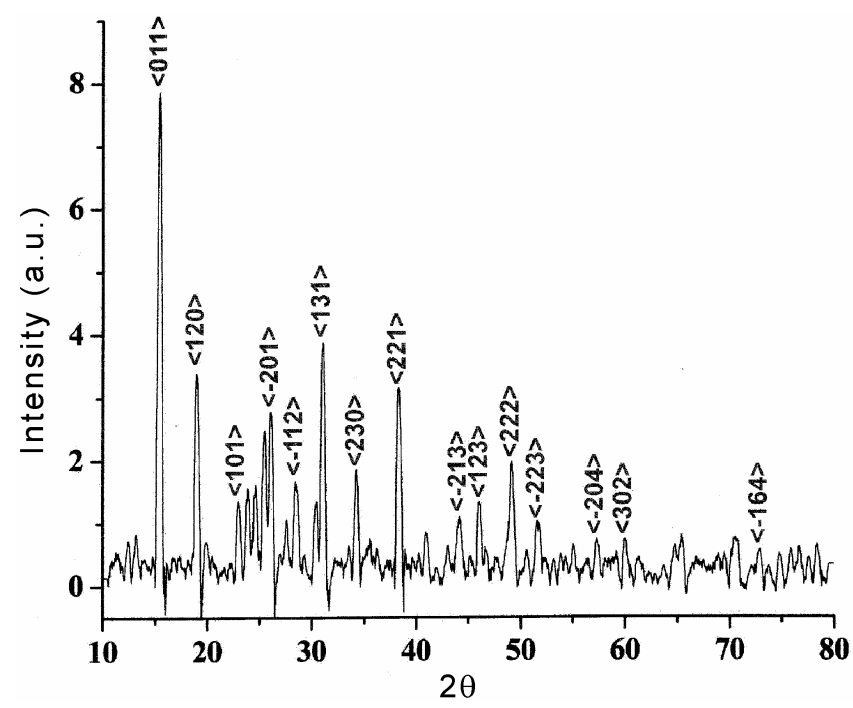

Figure 4. X-ray diffractogram of calcium cadmium iodate.

Table 4. Calculated unit cell parameters.

\begin{tabular}{llll}
\hline Parameter & \multicolumn{1}{c}{$\mathrm{Ca}\left(\mathrm{IO}_{3}\right)_{2}$} & \multicolumn{1}{c}{$\mathrm{Cd}\left(\mathrm{IO}_{3}\right)_{2}$} & $\mathrm{Ca}_{1-x} \mathrm{Cd}_{x}\left(\mathrm{IO}_{3}\right)_{4}$ \\
\hline System & Monoclinic & Monoclinic & Monoclinic \\
a & $8.509 \AA$ & $5.8561 \AA$ & $6.931 \AA$ \\
b & $10.027 \AA$ & $17.470 \AA$ & $12.8759 \AA$ \\
$\mathrm{c}$ & $7.512 \AA$ & $5.582 \AA$ & $6.4784 \AA$ \\
$\mathrm{V}$ & $638.213(\AA)^{3}$ & $571.063(\AA)^{3}$ & $578.150(\AA)^{3}$ \\
\hline
\end{tabular}

given in table 4 and employing the Vegard's law. The molecular formula of the crystals grown can, therefore, be written as $\mathrm{Ca}_{0.6} \mathrm{Cd}_{0.4}\left(\mathrm{IO}_{3}\right)_{4} \cdot n \mathrm{H}_{2} \mathrm{O}$ on the basis of XRD and FTIR. Here $n$ is the number of water molecules.

\subsection{Thermal analysis}

TGA and DTA studies of mixed iodate crystals were carried out at NCL, Pune. Figures 5(a) and (b) represent the TGA and DTA curves, respectively. It shows that the compound is stable up to $110^{\circ} \mathrm{C}$. The initial $18.4 \%$ weight loss occurs due to loss of 10 water molecules in the temperature range $110-140^{\circ} \mathrm{C}$ and a further $3 \cdot 2 \%$ weight loss in the temperature range $220-260^{\circ} \mathrm{C}$. This loss of weight is due to loss of coordinated 2 water molecules. There is no further weight loss up to $580^{\circ} \mathrm{C}$. Further $65 \%$ weight loss in the temperature range $580-670^{\circ} \mathrm{C}$ is due to decomposition of crystals and may be loss of iodine and some oxygen from the anhydrous mixed iodate crystals. Again in the temperature range $700-760^{\circ} \mathrm{C}$, there is $10 \cdot 19 \%$ weight loss indicating decomposition of reaction producing mixture of $\mathrm{CaO}$ and $\mathrm{CdO}$.

Molecular weight of the crystal,

$\mathrm{Ca}_{0.6} \mathrm{Cd}_{0.4}\left(\mathrm{IO}_{3}\right)_{4} \cdot 12 \mathrm{H}_{2} \mathrm{O} \quad: 985$

Molecular weight of $\mathrm{Ca}_{0 \cdot 6} \mathrm{Cd}_{0.4}\left(\mathrm{IO}_{3}\right)_{4} \quad: 769$

Weight of 12 moles of $\mathrm{H}_{2} \mathrm{O}: 216$

Amount of $\mathrm{Ca}_{0.6} \mathrm{Cd}_{0.4}\left(\mathrm{IO}_{3}\right)_{4}$ in the crystal : $78.1 \mathrm{wt} \%$

Water of crystallization : $21.9 \mathrm{wt} \%$

Wt. loss observed in the first two : $18 \cdot 47+3 \cdot 21$ temperature regimes $\quad=21.68 \%$

The calculation shows that the molecular formula of the grown $\mathrm{Ca}_{0.6} \mathrm{Cd}_{0.4}\left(\mathrm{IO}_{3}\right)_{4} \cdot n \mathrm{H}_{2} \mathrm{O}$ crystal as determined from XRD and FTIR can be written as $\mathrm{Ca}_{0 \cdot 6} \mathrm{Cd}_{0 \cdot 4}\left(\mathrm{IO}_{3}\right)_{4}$. $12 \mathrm{H}_{2} \mathrm{O}$. 

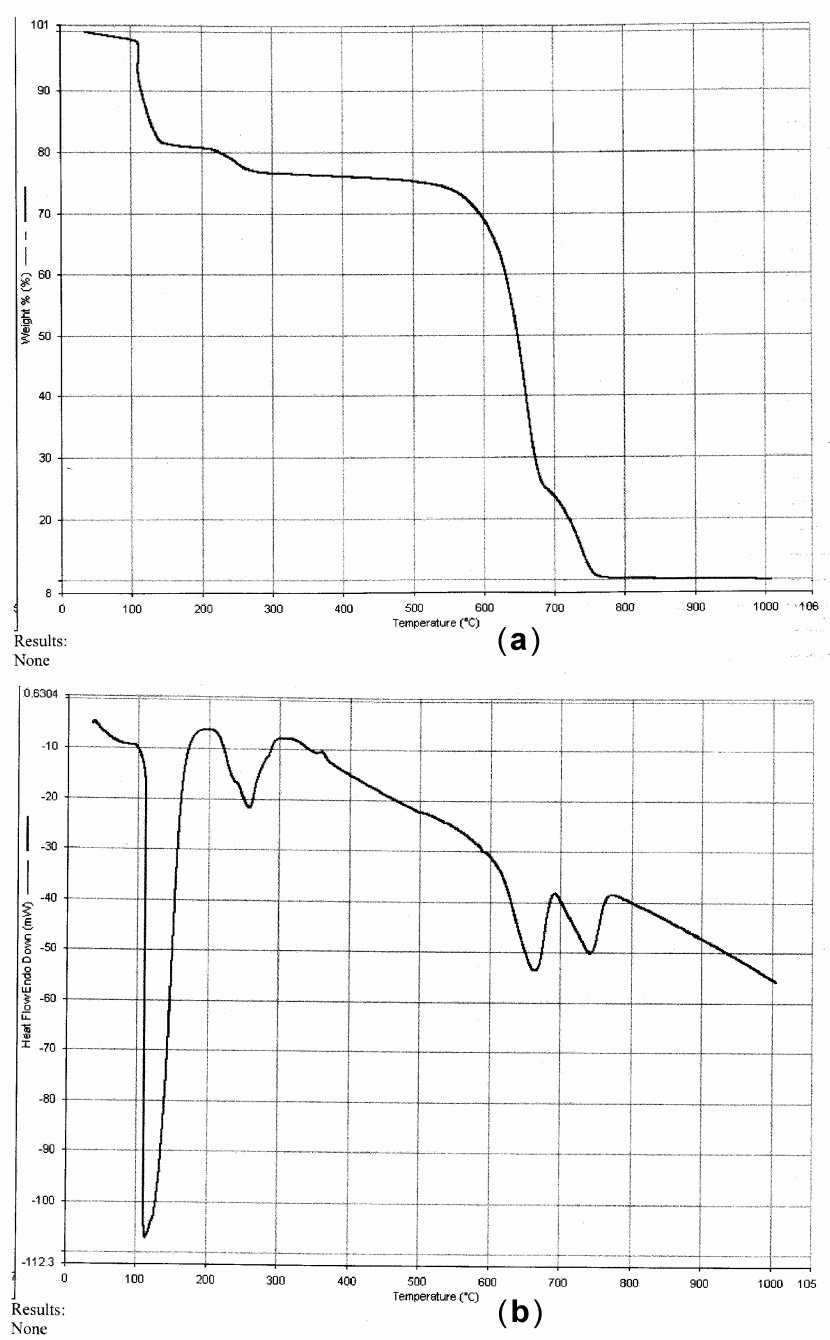

Figure 5. (a) TGA curve of calcium cadmium iodate crystal and (b) DTA curve of calcium cadmium iodate crystal.

DTA curve of the same compound shows its peaks at $110-140^{\circ} \mathrm{C}, 220-260^{\circ} \mathrm{C}, 580-670^{\circ} \mathrm{C}$ and $700-760^{\circ} \mathrm{C}$.

\section{Conclusions}

From the above studies we observe that

(I) Gel growth technique is suitable for growing crystals of calcium cadmium iodate.
(II) Different habits of calcium cadmium iodate crystals can be obtained by changing parameters like gel density, gel aging, $\mathrm{pH}$ of gel, concentration of reactants, concentration of impurities etc.

(III) Well known Liesegang phenomenon is observed in the growth of calcium cadmium iodate crystals.

(IV) Chemical compositions of the grown crystal by EDAX match well with the theoretical calculation from molecular formula.

\section{Acknowledgements}

The authors are grateful to Prof. S A Patil, Department of Physics, Pratap College, Amalner, for providing laboratory facilities. Our special thanks are due to Prof. P P Patil, Director, Physical Sciences, North Maharashtra University, Jalgaon, for help in XRD analysis. Also we thank Late Prof. R U Vaidya, Pratap College, Amalner, for fruitful discussions. One of the authors (SLG) sincerely thanks the University Grants Commission, New Delhi, for the award of a teacher fellowship under the Faculty Improvement Programme.

\section{References}

Armington A F and O'Connar J J 1968 J. Cryst. Growth 3/4 367

Bach H and Kuppers H 1978 Acta Crystallogr. B34 263

Blank Z 1973 J. Cryst. Growth 18281

Blank Z and Brenner W 1969 Nature 22279

Blank Z, Brenner W and Okanoto Y 1969 Mater. Res. Bull. 3 829

Joshi M S and Trivedi S G 1983 Indian J. Pure \& Appl. Phys. 21435

Kurtz S K and Perry T T 1968 J. Appl. Phys. 393798

Morosin B, Bergman J G and Crane G R 1973 Acta Crystallogr. B29 1067

Nakamoto K 1970 Infrared spectra of inorganic and coordination compounds (New York: John Wiley and Sons Inc) 2nd edn

Patel A R and Venkateswara Rao A 1978 J. Cryst. Growth 43 351

Ranadive D, Blank Z, Brenner W and Okamoto Y 1969 Nature 223829

Sangwal K and Patel A R 1974 J. Cryst. Growth 23282

Shitole S J and Saraf K B 2001 Bull. Mater. Sci. 5461 